\title{
PENYULUHAN SISTEM KELEMBAGAAN EKO WISATA BERDASARKAN PERATURAN KEBIJAKAN DI DESA AIK BERIK KECAMATAN BATUKLIANG UTARA KABUPATEN LOMBOK TENGAH
}

Sulman Aliansyah ${ }^{1}$, Yuliana ${ }^{2}$, Izzaturrahmah ${ }^{3}$, Subhan ${ }^{4}$, Sofiya Laras . $\mathrm{K}^{5}$, Indah Febriantari ${ }^{6}$, Rahayu Sya'baniari ${ }^{7}$, Akhmad Dafiz Rathomy ${ }^{8}$, Baiq Tria Arinda $E^{9}$, Gita Annora ${ }^{10}$, Markum ${ }^{11 *}$

$1,8,9$ )Fakultas Hukum, Universitas Mataram

1,2,4)Fakultas Keguruan dan IImu Pendidikan, Universitas Mataram

${ }^{3}$ Fakultas Peternakan,Universitas Mataram

6,10Fakultas MIPA, Universitas Mataram

${ }^{7}$ Fakultas Ekonomi Dan Bisnis, Universitas Mataram

Dosen Kehutanan, Fakultas Kehutanan, Universitas Mataram

${ }^{*}$ Co-Author Email: Markum.exp@gmail.com

\begin{abstract}
ABSTRAK. Ekowisata merupakan salah satu kegiatan pariwisata yang berwawasan lingkungan dengan mengutamakan aspek konservasi alam, aspek pemberdayaan social, budaya, ekonomi masyarakat lokal serta aspek pembelajaran dan pendidikan. Oleh sebab itulah suatu Wilayah yang sudah di tetapkan menjadi sebuah Wilayah/Desa Ekowisata tentunya memberikan dampak yang positif bagi masyarakat setempat, jika bisa mengelolannya dengan baik, terutama masalah kelembagaan dari Ekowisata tersebut. Oleh sebab itulah kami mencoba memberikan sebuah edukasi kepada masyarakat di Desa Aik Berik untuk bisa memahami tentang kelembagaan Ekowisata sesuai dengan peraturan Menteri dalam Negeri No 33 tahun 2009 tentang pedoman pengembangan Ekowisata Daerah. Adapun metode edukasi yang kami lakukan, kami memberikan sebuah penyuluhan kepada masyarakat, dengan cara mendatangi para warga Desa Aik Berik, baik yang terlibat dalam pengembangan Ekowisata tersebut, maupun warga biasa. Dengan adannya edukasi seperti ini, kami beraharap kepada warga yang hidup di kawasan Daerah Ekowisata Desa Aik Berik, untuk bisa menjaga kelestarian alam,, dan bisa memberi kenyamanan kepada para pengunjung.
\end{abstract}

Kata Kunci: (minimal 3 kata)

\section{PENDAHULUAN}

Ekowisata merupakan salah satu kegiatan pariwisata yang berwawasan lingkungan dengan mengutamakan aspek konservasi alam, aspek pemberdayaan sosial budaya ekonomi masyarakat lokal, dan aspek pembelajaran serta pendidikan. Ekowisata dapat dijadikan sebagai ajang pendidikan dan penyadaran bagi para wisatawan, masyarakat lokal serta stakeholder lain yang terlibat tentang pentingnya lingkungan hidup, penghargaan konsep-konsep preservasi dan konservasi terhadap lingkungan dan budaya local (Wisnu dwi atmoko, 2008). Publikasi yang dikeluarkan The International Ecotourism Society (TIES) tahun 2007 menyebutkan bahwa pada tahun 2004 pertumbuhan ekowisata secara global mencapai 3 kali lebih cepat dibandingkan industri pariwisata lainnya. Ekowisata sebagai kegiatan yang terintegrasi, merupakan keseimbangan antara menikmati dan upaya mempertahankan keindahan alam dengan perlibatan dan partisipasi masyarakat setempat dan wisatawan di dalamnya. Ekowisata dapat dilihat sebagai suatu konsep pengembangan pariwisata berkelanjutan yang bertujuan untuk mendukung upaya-upaya pelestarian 
lingkungan (alam dan budaya) dan meningkatkan partisipasi masyarakat dalam pengelolaannya (TIES dalam Dirawan, 2003) dalam (Wisnu dwi atmoko, 2008).

Ekowisata sendiri tak jarang ditemukan dibeberapa tempat, termasuk di suatu desa tertentu. Contohnya ekowisata yang terdapat dli Lombok yaitu ekowisata yang ada di desa Aik Berik Kecamatan Batukliang Utara Kabupaten Lombok Tengah. Salah satu ekowisata yang telah tersedia di desa ini adalah air terjun dan objek wisata lainnya. wilayah yang masih alami, yang tidak hanya mengembangkan aspek lingkungan dalam hal konservasi saja, namun juga memberikan keuntungan bagi masyarakat sekitar, sebagai sa-lah satu upaya pengembangan pedesaan untuk meningkatkan perekonomian lokal, dimana masyarakat di kawasan tersebut merupakan pemegang kendali utama (Dhayita rukthi tanaya,2014).

Akan tetapi permasalahan di desa Aik Berik ini adalah kurangnya kesadaran dan pemahaman masyarakat dalam pengembangan tentang ekowisata yakni kegiatan perencanaan, pemanfaatan dan pengendalian ekowisata disertai dengan ketidak dilakukannya suatu kegiatan penyuluhan atau sosialisai oleh desa bahwa adanya peraturan perundang-undangan tentang sistem ekowisata yakni peraturan menteri dalam nergeri nomer 33 tahun 2009 tentang pedoman pengembangan ekowisata di daerah, dimana mengenai pengembangan ekowisata terdapat beberapa pasal yang menjadi acuan dalam pelaksanaanya. Kebijakan pengembangan ekowisata harus dapat memperhatikan banyak sektor, disiplin ilmu dan berorientasi pada research based sehingga dapat mengakomodasi kepentingan para pelaku dan sektor terkait secara terpadu, serta tidak bersifat instant (Ardiwidjaja, 2003) dalam (Wisnu dwi atmoko, 2008). Sesuai dengan apa yang di sampaikan oleh Ardiwidjaja bahwa dalam pengembangan ekowisata memang harus dilibatkan banyak sektor di karenakan untuk melancarkan pengembangan dari ekowisata tersebut dan juga percuma jika memang banyak sektor yang terlibat namun tanpa adanya disiplin ilmu tentang pengembangan dari ekowisata, terutama ilmu mengenai pengetahuan tentang adanya peraturan perundang-undangan tentang sistem ekowisata yakni peraturan menteri dalam nergeri nomer 33 tahun 2009 tentang pedoman pengembangan ekowisata di daerah, karena tanpa adanya disiplin ilmu tersebut, maka penegembangan dari ekowisata yang telah direncanakan akan mengalami hambatan. Hal ini yang akan menyebabkan ketidaklancaran dalam pengembangan ekowisata tersebut.

Oleh karena itu, kami dari mahasiswa KKN-T Universitas Mataram, akan mengoptimalkan pengembangan ekowisata di Desa Aik Berik Kecamatan Batukliang Utara Kabupaten Lombok Tengah dengan mengajak masyarakat untuk hadir dalam berpartisipasi demi kemajuan desa. Hal ini yang mendasari kami untuk mengangkat salah satu judul kegiatan KKN adalah tentang "penyuluhan tentang sistem kelembagaan ekowisata berdasarkan peraturan kebijakan di Desa Aik Berik Kecamatan Batukliang Utara Kbupaten Lombok Tengah".

\section{METODE PELAKSANAAN}

Metode yang digunakan untuk mengoptimalkan pengembangan ekowisata dengan melakukan penyuluhan atau sosialisasi sistem kelembagaan ekowisata berdasarkan perundang-undangan yang ada. Metode Penyuluhan atau Sosialisasi dilakukan secara nonformal (door to door), dengan mendatangi beberapa rumah Kepala Dusun setempat sebagai titik kumpul. Pemberian materi kepada masyarakat tentang sistem kelembagaan ekowisata berdasarkan perundang-undangan yang sesuai dengan peraturan menteri dalam negeri tentang pedoman pengembangan ekowisata di daerah yaitu Peraturan Menteri Dalam Negeri Nomer 33 tahun 2009 tentang pedoman pengembangan ekowisata di daerah, dengan materi penyuluhan berupa, pertimbangan menteri 
dalam negeri bahwa ekowisata merupakan potensi sumber daya alam, lingkungan serta keunikan alam dan budaya, yang dapat menjadi salah satu sektor unggulan daerah yang belum di kembangkan secara optimal dan dalam pengembangan ekowisata secara optimal di daerah perlu strategi perencanaan, pemanfaatan, pengendalian, penguatan kelembagaan dan pemberdayaan masyarakat dengan memperhatikan kaidah-kidah sosial, ekonomi, ekologi, dan melibatkan pemangku kepentingan. Pertimbangan ini berdasarkan undang-undang nomer 5 tahun 1990 tentang konservasi sumber daya alam hayati dan ekosistemnya (lembaga negara republik Indonesia tahun 1990 nomer 49, tambahan lembaran negara republik Indonesia nomer 3419) dan beberapa peraturan perundang-undangan yang lain terkain pemberdayaan lingkungan serta peraturan pemeritah tentang pariwisata. Menteri dalam negeri menetapkan bahwa penegembangan ekowisata adalah kegiatan perencanaan, pemanfaatan dan pengendalian ekowisata, dimana yang menjadi pelaku ekowisata adalah pemerintah, pemerintah daerah, dunia usaha, dan masyarakat yang bergerak di bidang wisata yang di danai oleh anggaran pendapatan dan belanja negara dan sumber lainnya yang sah dan tidak mengikat. Peraturan menteri ini mulai berlaku pada tanggal yang di tetapkan (7 juli 2009). Selain itu diberikan juga makalah kepada peserta penyuluhan untuk memfokuskan dan memudahkan serta memantapkan pemahaman tentang isi materi yang disampaikan.

\section{HASIL DAN PEMBHASAN}

Sesuai dengan hasil survei yang telah dilakukan pada Desa Aik Berik Kecamatan Batukliang Utara Kabupaten Lombok Tengah, diketahui bahwa desa tersebut memiliki potensi ekowisata yang sangat bagus terutama pada ekowisata air terjun. Terutama melihat dari masih banyaknya masyarakat yang kurang mengetahui dan kurang faham tentang bagaimana pengembangan tentang ekowisata, apalagi masih banyak yang belum tahu bahwa ada peraturan perundang-uandangan yang mengatur tentang ekowisata yaki peraturan menteri dalam negeri tentang pengembangan ekowisata. Oleh karena itu, dilakukan penyuluhan sistem kelembagaan ekowisata berdasarkan peraturan perundang-undangan yakni peraturan Menteri dalam Negeri nomer 33 tahun 2009 tentang pedoman pengembangan ekowisata di daerah, yang dimana lebih di fokuskan terhadap pengembanga ekowisata yakni kegiatan perencanaan, pemanfaatan dan pengendalian ekowisata di desa Aik Berik Kecamatan Batukliang Utara Kabupaten Lombok Tengah. Hal ini dilakukan dengan harapan dapat memberikan pemahaman dan menumbuhkan kesadaran bagi masyarakat desaa Aik Berik agar dapat mengetahui cara pengembangan ekowisata yang baik dan benar yakni cara perencanaa, pemanfaatan dan pengendalian ekowisata yang ada dengan tujuan kemajuan desa Aik Berik Kecamatan Batukliang Utara Kabupaten Lombok Tengah.

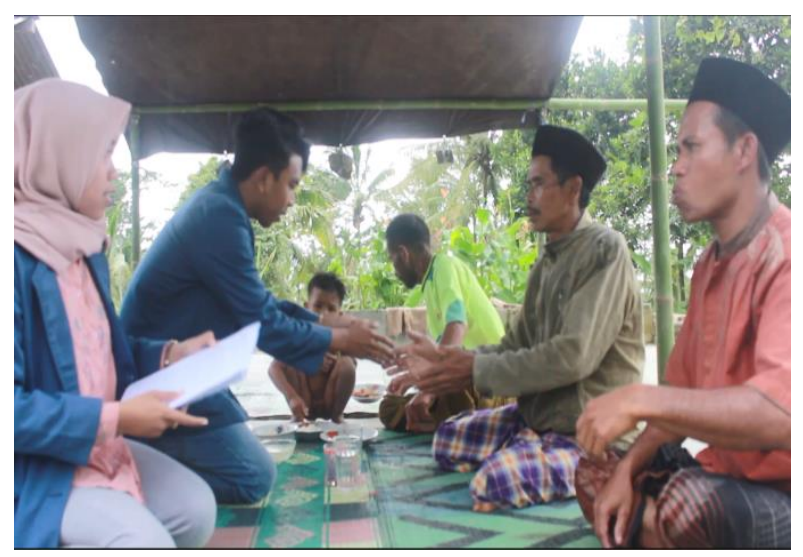




\section{Gambar 1. Kegiatan penyuluhan di Dusun Seganteng Desa Aik Berik}

Penyuluhan yang dilakukan ini adalah dengan cara nonformal (Door To Door), dan tidak dilaksanakan secara formal, hal ini dikarenakan cuaca dan kondisi yang tidak menentu selama melaksanakan kuliyah kerja nyata (KKN) di desa Aik Berik Kecamatan Batukliang Utara Kabupaten Lombok Tengah. Pertama mendatangi beberapa rumah Kepala Dusun setempat sebagai titik kumpul yang sebelumnya telah dikomunikasikan bahwa akan dilakukan penyuluhan. Ditetapkan tema penyuluhan yakni sistem kelembagaan ekowisata oleh desa berdasarkan peraturan perundang-undangan yang ada yakni peraturan menteri dalam negeri nomer 33 tahun 2009 tentang pedoman pengembangan ekowisata di daerah , tema ini dipilih dikarenakan hasil survei yang telah dilakukan di dapati bahwa masih banyak warga di desa Aik Berik Kecamatan Batukliang Utara Kabupaten Lombok Tengah ini yang belum memahami dan menyadari adanya peraturan perundang-undangan tentang ekowisata dalam kegiatan perencanaan, pemanfaatan dan pengendalian ekowisata, dengan perencanaan ekowisata yang merupakan bagian dari perencanaan pariwisata daerah, kemudian pemanfaatan ekowisata mencakup beberapa hal yakni pengelolaan kawasan ekowisata, pemeliharaan ekowisata, pengamanan kawasan ekowisata dan penggalian potensi kawasan ekowisata baru, terakahir mengenai pengendalian ekowisata dilakukan antara lain terhadap fungsi kawasan, pemanfaatan ruang, pembangunan sarana dan prasarana, kesesuaian spesifikasi konstruksi dengan desain teknis dan kelestarian kawasan ekowisata dan pengendalian ekowisata ini dilakukan melalui antara laian pemberian izin pengembangan ekowisata, pemantauan pengembangan ekowisata, penertiban atas penyalahgunaan izin pengembangan ekowisata dan penanganan serta penyelesaian masalah atau konflik yang timbul dalam penyelenggaraan ekowisata. Hal ini dilakukan dengan harapan dapat mengurangi permasalahan yang ada. Selain materi yang disampaikan yakni tentang sistem kelembagaan ekowisata berdasarkan peraturan perundang-undangan yang ada, diberikan juga berupa makalah kepada para peserta penyuluhan, agar lebih memfokuskan para peserta dalam pemberian materi serta untuk memantapkan pemahamannya terhadap isi materi tersebut.

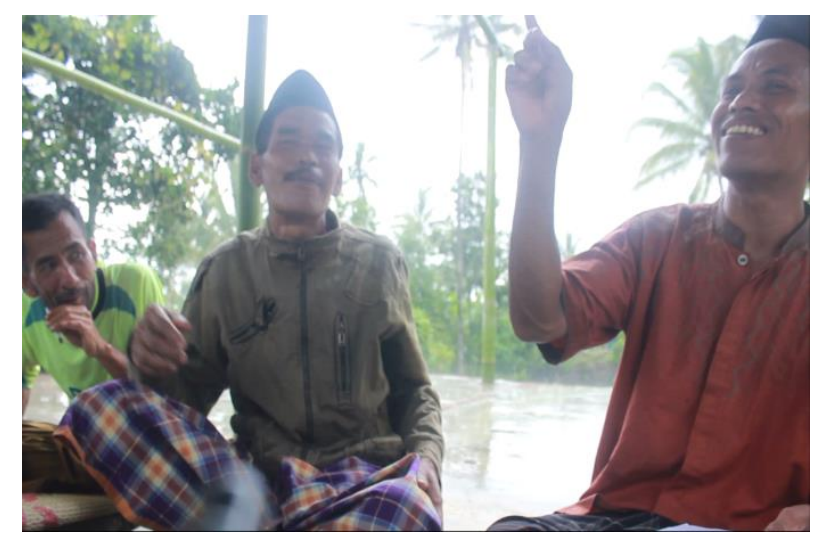

Gambar 2. Antusias Warga saat di berikan penyuluhan

Setelah pemberian materi kepada para peserta penyuluhan. Terlihat bahwa para peserta baru mengetahui adanya peraturan seperti itu, sehingga para peserta pun memberikan respon yang baik ketika di jelaskan tentang peraturan menteri dalam negeri nomer33 tahun 2009 tentang pedoman pengembangan ekowisata di daerah, bahkan para peserta meminta agar seharusnya dibuatkan 
suatu forum khusus untuk pembahasan seperti ini, agar dapat memahami lebih dalam lagi mengenai adanya peraturan perundang-undangan tentang ekowisata, karena desa Aik Berik Kecamatan Btukliang Utara Kabupaten Lombok Tengah merupakan daerah ekowisata, jadi sangat disayangkan jikalau masih banyak masyarakatnya yang belum paham tentang peraturan tersebut. Pemahaman yang mereka dapatkan akan mereka pergunakan dengan sebaik-baiknya untuk pengembangan ekowisata kedepannya, dengan harapan nantinya desa Aik Berik Kecamatan Batukliang Utara Kabupaten Lombok Tengah ini dapat dikenal lebih luas lagi, bahkan oleh seluruh dunia.

\section{KESIMPULAN DAN SARAN}

\section{Kesimpulan}

Berdasarkan hasil dan pembahasan dapat disimpulkan bahwa desa Aik Berik Kecamatan Batukliang Utara Kabupaten Lombok Tengah memiliki potensi ekowisata yang sangat melimpah khususnya pada ekowisata air terjun, karena di desa Aik Berik Kecamatan Batukliang Utara Kabupaten Lombok Tengah banyak terdapat air terjun baik yang telah dikenal luas maupun yang masih belum diketahui secara luas. Namun permasalahannya adalah belum banyak yang mengetahui tentang peraturan yang berlaku di perundang-undangan, sehingga kebanyakan darinya melakukan kesalahan dalam pengelolaan dan pengembangan ekowisatanya, dan setelah kami melakukan penyuluhan tentang sistem kelembagaan ekowisata berdasarkan peraturan peurundang-undangan yang ada yakni peraturan menteri dalam negeri nomer 33 tahun 2009 tentang pedoman pengembangan ekowisata di daerah, terlihat sekali dari jumlah masyarakat yang ikut berpartisipasi dalam kegiatan penyuluhan tersebut dan antusias para masyarakat dalam menerima materi yang diberikan dan dan berniat untuk memperbaikai kesalahan tersebut. Jadi terlihat bahwa dengan materi yang disampaikan dapat memberikan pemahaman dan kesadaran kepada masyarakat tentang pentingnya pengelolaan dan pengembangan ekowisata dengan tidak lupa memperhatikan peraturan perundang-undangan yang ada.

\section{Saran}

Perlunya diadakan suatu forum khusus untuk lebih meningkatkan pemahaman dan kesadaran kepada masyarakat di desa Aik Berik Kecamatan Batukliang Utara Kabupaten Lombok Tengah terhadap adanya peraturan perundangundangan tentang ekowisata.

\section{UCAPAN TERIMAKASIH}

Terimakasih disampaikan kepada LPPM yang telah memberikan ijin melaksanakan KKN, kepada Kepala Desa Aik Berik dan perangkatnya, serta para masyarakat setempat, yang telah memberikan kesempatan dan juga partisipasinya atas kelancaran dari program kami.

\section{REFERENSI}

Arinda Sukma. 2012. Pengembangan, Partisipasi Local Dan Tantangan Ekowisata.Fakultas Pariwisata, Universitas Udayana.Cakra Press.

Atmoko Dwi Wisnu.2008. Studi Prospek Pengembangan Ekowisata Pada Kawasan Sekitar Kars Gombong Selatan Dalam Mendukung Keberlanjutan Wilayah. Jurusan Perencanaan Wilayah Dan Kota, Fakultas Teknik, Universitas Diponegoro. 
Aulia N. A., Hakim L.2017.Pengembangan Potensi Ekowisata Sungai Pekalen Atas, Desa Ranu Gedang, Kecamatan Tiris, Kabupaten Probolinggo.Vol.05. No.03. 11 Maret 2019.

Baskoro Probo S. M. 2016. Pengelolaan Kawasan Ekowisata Berbasis Masyarakat Serta Implikasinya Terhadap Ketahanan Masyarakat Desa Sukarara. Vol.05 No.02. 11 Maret 2019.

Basyuni M.,Bimantara Y.,Selamet B.,Thoha Siddik. 2016. Identifikasi Potensi Dan Strategi Pengembangan Ekowisata Mangrove Di Desa Lubuk Kertang, Kecamatan Brandan Barat, Kabupaten Langkat Sematera Uatara. Vol. 01. No.01. 11 Maret 2019.

Hijriati Emma, Mardiana R. 2014. Pengaruh Ekowisata Berbasis Masyarakat Terhadap Perubahan Kondisi Ekologi, Sosial Dan Ekonomi Di Kampung Batusushunan Sukabumi. Vol.02. No.03. 11 Maret 2019.

Mukaryanti, Saraswati A.2005. Pengembangan Ekowisata Sebagai Pendekatan Engelolaan Sumberdaya Pesisir Berkelanjutan. Vol.06. No. 02. 11 Maret 2019.

Peraturan menteri dalam negeri nomer 33 tahun 2009 tentang pedoman pengembangan ekowisata di daerah.

Prihanta Wahyu, Syarifuddin A.Zainuri M.A.2017. Pembentukan Kawasan Ekonomi Melalui Pengembangan Ekowisata Berbasis Masyarakat. Vol.14.11 Maret 2019.

Rahayu A., Rifai A.,Malinda N. I.2013. Pengelolaan Ekowisata Di Kawasan Hutan Pendidikan Gunung Wallet Fakultas Kehutanan Institute Pertanian Bogor.

Revalda A.2016. Pengembangan Ekowisata Berbasis Masyarakat Di Kepulauan Banda, Kabupaten Maluku Tengah.Vol.10.No.01. 11 Maret 2019.

Sahureka M. Lelloltery H., Hitipeuw Ch.J.2016. Implementasi Pengembangan Ekowisata Berbasis Masyarakat Di Hutan Lindung Gunung Sirimau Kota Ambon.

Tanaya Rukti D, Rudiarto Iwan.2014. Potensi Pengembangan Ekowisata Berbasis Masyarakat Dikawasan Rawa Pening Kabupaten Semarang.Vol.03 No.01.11 Maret 2019. 